\title{
The Key Application Technology of Desulfurized Gypsum in Dry- Mixed Mortar
}

\author{
Guangxu Fang *, Jin Pan, Rui Ma, Huan Wang, Jipeng Wang \\ Changji State Product Quality Inspection Institute ChangJi XinJiang 831100 China
}

\begin{abstract}
In this paper, in view of the problem of low early and late strength of dry-mixed mortar prepared by cement-fly ash-slag powder composite cementing system, the ratio of mixing fly ash and slag powder to replace cement is $70 \%$. To study the effect of desulfurization gypsum (FGD) on improving the activity of the system. The results show that adding desulfurized gypsum, which accounts for $6 \%$ to $8 \%$ of the total mass of the cementitious material, has no adverse effect on the workability and can significantly improve the compressive resistance of the slurry. Strength and tensile bonding strength, shrinkage rate is reduced by more than $10 \%$, and the ability to resist carbonization is improved to make the mortar volume more stable.
\end{abstract}

Key words: Desulfurized gypsum, dry-mix mortar, fly ash, slag powder.

\section{Introduction}

Ready-mixed mortar is one of the key projects implemented in China in recent years. Although mineral admixtures such as fly ash and slag powder have been widely used in dry-mixed mortars, mortars mixed with fly ash and slag powder, especially mortars mixed with large amounts of fly ash and slag powder, have obvious early mechanical properties Reduction seriously restricts the large-scale application of fly ash and slag powder in mortar. Desulfurized gypsum is an industrial by-product gypsum obtained after flue gas desulfurization in coalfired or oil-fired power plants [1]. Its main components and physical and chemical properties are basically the same as natural gypsum, with higher purity and smaller particle size. Since desulfurized gypsum contains water with a mass fraction of about $10 \%$, it also contains impurities such as fly ash, organic carbon, calcium carbonate, calcium sulfite, and soluble salts composed of sodium, potassium, magnesium sulphate or chloride. Therefore, the application of desulfurized gypsum is subject to certain restrictions, and a large amount of desulfurized gypsum is discarded and stored. This article proposes to use desulfurized gypsum as a modifier of the cement-fly ash-slag powder composite cementing system in a large amount of fly ash-slag powder dry-mix mortar to stimulate the activity of fly ash and slag powder, thereby the idea of improving the performance of drymixed mortar, and researching related issues through experiments.

\section{Experimental Design}

\subsection{Raw materials}

Two types of fly ash are used: coarse fly ash from Zhengzhou Taixiang Thermal Power Co., Ltd. and lowcalcium fly ash from Luoyang Power Plant [2]. The coarse fly ash of Zhengzhou Taixiang Thermal Power Co., Ltd. is ground to the specified time with a standard laboratory ball mill and divided into four types: undisturbed fly ash, ground fly ash (milled for 10 minutes), and ground fly ash (Grinding for 20min), grinding fly ash (grinding for $30 \mathrm{~min}$ ). The chemical properties of fly ash are shown in Table 1. The flue gas desulfurization gypsum adopts Zhengzhou Taixiang Thermal Power Co., Ltd., with a water content of $10.5 \%$; it is dried in an oven at $60^{\circ} \mathrm{C}$ for use in the laboratory.

Table 1. Chemical composition of raw materials

\begin{tabular}{|c|c|}
\hline Material name & $\mathrm{CaO} \mathrm{SiO} \mathrm{Al}_{2} \mathrm{O}_{3} \mathrm{Fe}_{2} \mathrm{O}_{3} \mathrm{~K}_{2} \mathrm{ONa}_{2} \mathrm{O} \mathrm{SO}_{3} \mathrm{MgO}$ Loss \\
\hline cement & $\begin{array}{lllllllll}60.0122 .21 & 5.51 & 2.88 & 0.80 & 0.08 & 2.50 & 2.60 & 3.21\end{array}$ \\
\hline $\begin{array}{l}\text { Zhengzhou } \\
\text { undisturbed fly ash }\end{array}$ & $\begin{array}{llllllll}1.20 & 60.0026 .00 & 5.00 & 0.78 & 0.40 & 0.45 & 0.40 & 5.50\end{array}$ \\
\hline $\begin{array}{c}\text { Luoyang Fly Ash } \\
\text { Flue gas }\end{array}$ & $\begin{array}{llllllll}0.80 & 57.5030 .00 & 5.20 & 0.66 & 0.41 & 0.38 & 0.45 & 3.60\end{array}$ \\
\hline $\begin{array}{l}\text { desulfurization } \\
\text { gypsum }\end{array}$ & 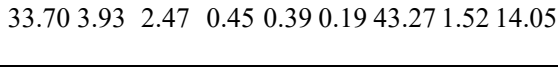 \\
\hline
\end{tabular}

\subsection{Method design}

Test specimen preparation and basic performance tests such as consistency, water retention, setting time, tensile bonding strength, compressive strength and shrinkage are 
all carried out with reference to "Test Methods for Basic Performance of Building Mortar" (JGJ/T70-2009), using a mortar mixer Stir, the stirring time is not less than $180 \mathrm{~s}$, and the tensile bond strength, compressive strength and shrinkage test block are cured according to the standard. Add water to the corresponding composite gelling system mortar according to the specified consistency, mix and form uniformly (the test mold is a compressive strength test mold), remove the mold after 24 hours, and cure it in a standard curing room to the specified age, and terminate it with anhydrous ethanol for hydration, perform the following treatments on the sample after 3 days of hydration: 1) X-ray diffraction (XRD) sample and scanning electron microscope (SEM) sample. Crush the sample, select a slurry without artificial sand under an optical microscope for SEM observation, and grind the remaining slurry for XRD testing. 2) Samples for pore structure analysis [3]. The sample is broken up, the samples containing artificial sand and the slurry without artificial sand are selected under an optical microscope, and the number of the slurry is half, mixed evenly, and then the pore structure is analysed.

\subsection{Experimental protocol}

The experimental study of the cement-fly ashdesulfurized gypsum mortar system has explored the composition of cement, FA, and FGD through experiments [4]. The cement content is initially set at $10 \%-20 \%$ of the cementitious material, and FA is added. The amount is $10 \%$ to $60 \%$, and the FGD is $20 \%$ to $70 \%$; methyl cellulose ether is blended at $0.1 \%$ of the mass of the cementing material; polypropylene hybrid fibre is blended at $0.4 \%$ of the mass of the cement; aggregate the mixing amount is 3 times the mass of the cementitious material (1:3 mortar), and the water-binder ratio is uniformly adopted at 0.5 . The specific coordination ratio is shown in Table 2.

Table 2. Test mix ratio of mortar

\begin{tabular}{cccccccc}
\hline No. & Cement & FA & FGD & Sand & Water & MC & Fibber \\
\hline 1 & 0.10 & 0.60 & 0.30 & 3 & 0.50 & $0.1 \%$ & $0.4 \%$ \\
2 & 0.10 & 0.45 & 0.45 & 3 & 0.50 & $0.1 \%$ & $0.4 \%$ \\
3 & 0.10 & 0.30 & 0.60 & 3 & 0.50 & $0.1 \%$ & $0.4 \%$ \\
4 & 0.15 & 0.60 & 0.25 & 3 & 0.50 & $0.1 \%$ & $0.4 \%$ \\
5 & 0.15 & 0.45 & 0.40 & 3 & 0.50 & $0.1 \%$ & $0.4 \%$ \\
6 & 0.15 & 0.30 & 0.55 & 3 & 0.50 & $0.1 \%$ & $0.4 \%$ \\
\hline
\end{tabular}

\section{Results}

\subsection{The influence of Portland cement on the consistency of mortar}

Figure 1 shows the effect of Portland cement content change on the consistency of desulfurized gypsum-based mortar. It can be seen that as the amount of cement increases, the consistency of the mortar shows a linear increase trend [5]. The consistency of the desulfurized gypsum-based mortar without cement (reference mortar) is $63 \mathrm{~mm}$; when the cement content is $10 \%$, the mortar consistency increases significantly to $85 \mathrm{~mm}$; when the cement content is $20 \%$, the mortar consistency increases to $102 \mathrm{~mm}$; When the cement content is $30 \%$, the consistency of the mortar reaches $110 \mathrm{~mm}$, an increase of $75 \%$. This shows that cement can significantly increase the consistency of desulfurized gypsum-based mortar and improve the fluidity of desulfurized gypsum-based mortar; and as its content increases, the consistency of the mortar gradually increases and the fluidity gradually improves.

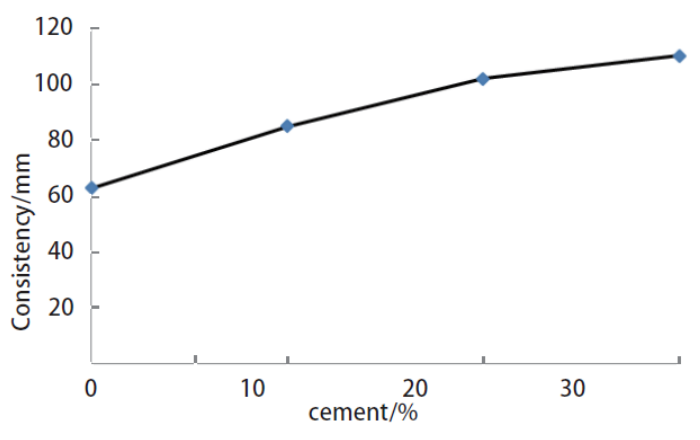

Figure 1. The effect of cement content change on the consistency of sulphurised gypsum-based mortar

\subsection{The influence of FGD on the performance of cement-fly ash-slag powder composite cementitious system mortar}

For the freshly mixed mortar mixture, when it reaches the specified consistency $(90-100 \mathrm{~mm})$, compared with the sample without FGD, when FGD is added to the cementfly ash-slag powder composite cementing system, the unilateral mortar is Water consumption and water retention have been reduced, but the change is not big; the change of setting time is more complicated. With the increase of FGD, the single-mixed fly ash gradually shortens, and the maximum shortens 30min; the singlemixed slag powder gradually increases, the maximum extension 40min; the two-compound mixed first lengthened and then shortened, and the change was within $\pm 20 \mathrm{~min}$. For hardened mortar paste, compared with samples without FGD, after FGD is mixed into the cement-fly ash-slag powder composite cementing system, the early and late compressive strength and tensile bonding strength of the mortar are both There are varying degrees of change [6]. When fly ash is mixed alone: FGD does not significantly improve the early compressive strength of the mortar, and too high a content will reduce its early compressive strength, but the compressive strength and tensile bonding strength of the mortar in the later period will be significantly improved; compared with single-mixed powder Compared with coal ash, when it is mixed with slag powder only: FGD improves the compressive strength of mortar in the early stage, but its later compressive strength and tensile bonding strength are less improved; compared with single-mixed fly ash or slag powder, the two When compounding: FGD significantly improves the compressive strength of the mortar in the early and late stages, and the increase rate of tensile bonding strength is equivalent to that of singlemixed slag powder; the increase rate of the early and late compressive strength and tensile bonding strength of the 
mortar reaches the maximum At the same time, the best content of desulfurization gypsum is $6 \%$.

\subsection{The influence of Portland cement on the bulk density of mortar}

Figure 2 shows the effect of Portland cement content change on the freshly mixed bulk density and 28d hardened bulk density of desulfurized gypsum-based mortar. It can be seen that after adding cement, the volume density of the freshly mixed desulfurized gypsum-based mortar has increased [7]. The volume density of the new benchmark mortar is $2010 \mathrm{~kg} / \mathrm{m}^{3}$; when the cement content is $10 \%$, the volume density of the fresh mortar is $2098 \mathrm{~kg} / \mathrm{m} 3$; when the cement content is $20 \%$, the volume density of the fresh mortar is $2060 \mathrm{~kg} / \mathrm{m}^{3}$; the cement content is at $30 \%$, the volume density of the freshly mixed mortar significantly increases to $2102 \mathrm{~kg} / \mathrm{m}^{3}$. With the change of cement content, the volume density of fresh mix fluctuates within the range of $50 \mathrm{~kg} / \mathrm{m}^{3}$. This shows that the incorporation of cement will increase the volume density of the freshly mixed desulfurized gypsum-based mortar, but the influence of the change in its mixing amount is relatively small.

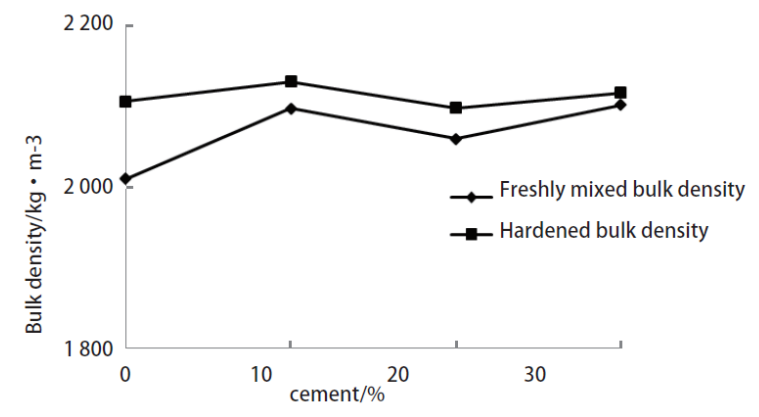

Figure 2. The influence of cement content change on the bulk density of desulfurized gypsum-based mortar

The $28 \mathrm{~d}$ hardened bulk density of desulfurized gypsumbased mortar changes with the increase of cement content and the trend is similar to that of freshly mixed bulk density [8]. When the cement content is $10 \%$, the hardened bulk density is $2131 \mathrm{~kg} / \mathrm{m}^{3}$, which is a slight increase of $25 \mathrm{~kg} / \mathrm{m}^{3}$ compared to the benchmark mortar; the hardened bulk density of the mortar with cement content of $20 \%$ is slightly reduced to $2099 \mathrm{~kg} / \mathrm{m}^{3}$; the cement content is $30 \%$ The hardened bulk density of the mortar increased to $2117 \mathrm{~kg} / \mathrm{m}^{3}$. With the change of cement content, the hardening volume density changes within $30 \mathrm{~kg} / \mathrm{m} 3$. This indicates that the change of cement content has a relatively small effect on the hardened bulk density.

\subsection{SEM image}

In this experiment, scanning electron microscopy (SEM) and scanning electron microscopy (SEM) were carried out on the cementitious material according to the mixing ratio of cement: fly ash: desulfurized gypsum=30:50:20 (mass ratio) and water-binder ratio of 0.3 . X-ray diffraction (XRD) analysis, the results are shown in Figures 3 and 4.

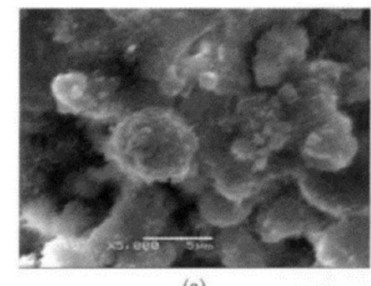

(a)

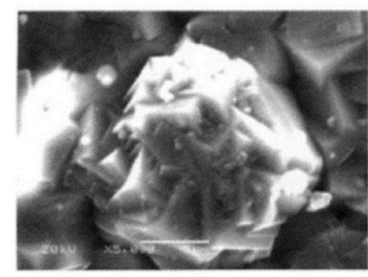

(c)

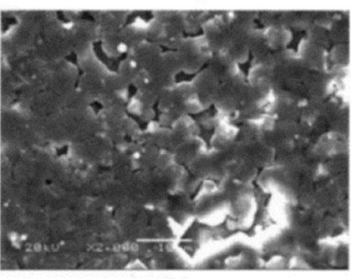

(b)

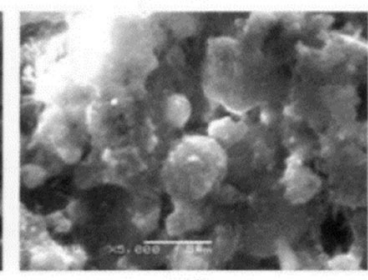

(d)
Figure 3. SEM image of hardened gel material

Figure 3(a) is the SEM image of the $3 d$ hardened body of Luoyang low-calcium fly ash (Class II undisturbed ash). It can be seen from Figure 3(a) that there is a small amount of needle-like hydration products between the particles, and the structure is very Loose, the wheel angles of spherical fly ash particles and lump gypsum particles are clearly visible; Figures 3(b) and 3(c) are SEM images of $38 \mathrm{~d}$ hardened body of Luoyang low-calcium fly ash (level II undisturbed ash). From Figures 3(b) and 3(c), it can be seen that the particles are irregular and the structure is loose as shown in Figure 3(b); a large amount of plate-like gypsum products or low-sulphur hydrated sulphur are deposited on the surface of spherical fly ash particles [9]. The calcium aluminate product is shown in Figure 3(c). The main elements of the plate-like substance are calcium, sulphur, oxygen and a small amount of silicon and aluminium according to the energy spectrum analysis; Figure $3(\mathrm{~d})$ is the $3 \mathrm{~d}$ hardening mixed with ground fly ash (Class II) The SEM image of the body, as can be seen from Figure 3(d): there is a certain amount of needle-like hydration products between the particles, the structure is looser, but denser than 3(a), spherical fly ash particles and lump gypsum The wheel angle of the particles is not clear. The XRD analysis of the cementitious material (Figure 4) shows that the cementitious material mixed with undisturbed ash and ground ash contains ettringite crystals and gypsum crystals in $3 \mathrm{~d}$ and $28 \mathrm{~d}$ hardened bodies; the cemented material mixed with fine ash $28 \mathrm{~d}$ hardened body The obvious increase of the baseline of the XRD pattern indicates the formation of a large amount of gel. 


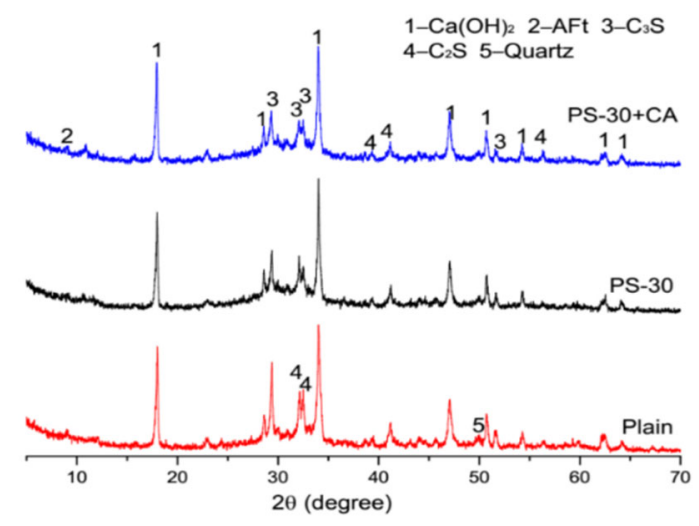

Figure 4. XRD pattern of hardened cementitious material

\section{Conclusion}

In a large amount of fly ash-slag powder dry-mix mortar, desulfurized gypsum not only directly stimulates the activity of fly ash and slag powder, but also accelerates fly ash and slag powder by promoting the hydration of cement the hydration reaction. Large-volume fly ash-slag powder dry-mixed mortar is a new type of green building material with excellent performance. It can not only effectively use industrial waste gas desulfurized gypsum, but also further promote the utilization of fly ash and slag powder, and reduce cement The consumption, energy saving and consumption reduction have achieved remarkable results, and the application prospects are broad, which are in line with the national circular economy strategy.

\section{References}

1. Liu Yin, Wang Haoyu, Guo Hao, et al. Research on optimization and performance of high-volume fly ash filling materials. Mining Research and Development, 40(3) (2020) 56-62.

2. Wang Chenxia, Liu Jun, Cao Fubo, et al. Experimental study on slag-fly ash recycled concrete under the coupling effect of freeze-thawcarbonization. Building Structure, 50(15) (2020) 4549.

3. Xie Tianyi, Lou Zongke, Huo Yizhen, et al. The effect of fly ash and slag on the fluidity and mechanical properties of channel lining mould bag concrete. Agricultural Research in the Arid Areas, 37(2) (2019) 74-79.

4. Wu Yonghua, Hu Yubo, Nan Feng, et al. The effect of fly ash on the corrosion resistance of alkaliactivated slag cementitious materials with hydrochloric acid. Bulletin of the Chinese Ceramic Society, 38(4) (2019) 15-22.

5. Jiao Xuemei, Qin Can, Gong Jingwei, et al. Analysis of hydration heat release of ordinary Portland cement-based cementitious material system with large amount of mineral admixtures. Hydropower, 45(11) (2019) 10-18.
6. Huai Jianfeng. Analysis of the influence of fly ash and ceramsite on concrete road performance. Comprehensive utilization of fly ash, 15(1) (2019) 57-60.

7. Li Bing, Wei Sha, Zheng Yiwen. Preparation and performance of desulfurized ash-based semi-light dry-mixed mortar. Non-metallic Minerals, 43(1) (2020) 15-20.

8. Wang Yan, Tong Yueping, Zhang Shaohui, et al. Effect of nano-clay on the properties of high-volume fly ash mortar. Industrial Construction, 50(2) (2020) 47-58.

9. Huang Qian, Tang Shuai, Chen Yibo, et al. The effect of nano-SiO2 on the properties of high-volume fly ash cement. Non-metallic Minerals, 43(2) (2020) 1728. 